\title{
An Assessment of Balance through Posturography in Healthy about Women: An Observational Study
}

\author{
Elena Escamilla-Martínez ${ }^{1}$, Ana Gómez-Maldonado ${ }^{1}$, Beatriz Gómez-Martín ${ }^{1}{ }^{\circledR}$, Aurora Castro-Méndez ${ }^{2}{ }^{\circledR}$, \\ Juan Antonio Díaz-Mancha ${ }^{3}$ and Lourdes María Fernández-Seguín ${ }^{3, * \text { (D) }}$ \\ 1 CPUEX, Centro Universitario de Plasencia, University of Extremadura, Avda. Virgen del Puerto 2, \\ 10600 Plasencia, Spain; escaelen@unex.es (E.E.-M.); anagmpodologa@gmail.com (A.G.-M.); \\ bgm@unex.es (B.G.-M.) \\ 2 Podiatry Department, University of Seville, C/Avicena s/n, 41009 Seville, Spain; auroracastro@us.es \\ 3 Physiotherapy Department, University of Seville, C/Avicena s/n, 41009 Seville, Spain; jdm@us.es \\ * Correspondence: lfdez@us.es; Tel.: +34-954-48-65-05
}

Citation: Escamilla-Martínez, E. Gómez-Maldonado, A.; GómezMartín, B.; Castro-Méndez, A.; Díaz-Mancha, J.A.; Fernández-Seguín, L.M. An Assessment of Balance through Posturography in Healthy about Women: An Observational Study. Sensors 2021, 21, 7684. https:// doi.org/10.3390/s21227684

Academic Editors: Maria Linden, Annica Kristoffersson and Marina Arkkukangas

Received: 17 October 2021 Accepted: 17 November 2021 Published: 19 November 2021

Publisher's Note: MDPI stays neutral with regard to jurisdictional claims in published maps and institutional affiliations.

Copyright: (c) 2021 by the authors. Licensee MDPI, Basel, Switzerland. This article is an open access article distributed under the terms and conditions of the Creative Commons Attribution (CC BY) license (https:// creativecommons.org/licenses/by/ $4.0 /)$.

\begin{abstract}
The incidence of falls in adults constitutes a public health problem, and the alteration in balance is the most important factor. It is necessary to evaluate this through objective tools in order to quantify alterations and prevent falls. This study aims to determine the existence of alteration of balance and the influence of age in a population of healthy women. Static posturography was performed on 49 healthy adult women with no history of falls in four different situations using the Romberg test with the NedSVE/IBV ${ }^{\circledR}$ platform. The variables studied were the body sway area and the anteroposterior and mediolateral displacements. The situation of maximum instability occurred in RGC ( $p=0.001)$, with a significant increase in anteroposterior oscillations regarding the ML $(p<0.001)$, with no correlation to age. Age alone does not influence the balance in the sample studied, other factors must come together to alter it. The joint cancellation of visual and somatosensory afferents could facilitate the appearance of falls, given that it is a situation of maximum instability. Proprioceptive training is interesting as a preventive strategy for falls.
\end{abstract}

Keywords: balance; falls; posturography; women; aging; NedSVE/IBV ${ }^{\circledR}$ platform

\section{Introduction}

Falls in older adults, whose fall incidence increases with age [1], constitute a major public health problem due to morbidity, mortality and the economic and emotional costs for the individual, their family and society [2-5]. The loss of independence due to immobility is the worst consequence suffered those who experience falls [6].

The etiology of falls is multifactorial, with impaired balance being the most important cause of falls [7-9]. Balance is achieved thanks to the interaction between sensory receptors located in the vestibular, visual and somatosensory systems, the Central Nervous System and the musculoskeletal reflex arcs [9].

It is necessary to study each of the three systems for a correct assessment and diagnosis of balance $[10,11]$. It is possible to train these systems partially or to use all three systems globally, with different methodologies reflected in the scientific field, therefore obtaining an improvement in postural control [12-15].

Static posturography provides sensitive information about the oscillations of the center of gravity that are generated in an upright static stance [16]. It is a fast, non-invasive and useful tool for screening for possible balance abnormalities [17].

We propose a study of balance via static posturography in healthy older women with no previous history of falls to determine: (1) whether there is an alteration in balance and in which component it occurs (visual (VIS), vestibular (VES) or somatosensory (SOM)); (2) whether balance changes with age; and (3) which of the variables studied (AP displacement, ML displacement or body sway area) undergoes the most changes. 


\section{Materials and Methods}

\subsection{Design}

A longitudinal cohort study was carried out following the ethical principles set out in the Declaration of Helsinki on studies with human subjects. The Bioethics Commission of the University of Extremadura approved the study (code project 16-3-20). All participants signed an informed consent as dictated by the Declaration of Helsinki.

This study was performed and reported according to the Strengthening the Reporting of Observational Studies in Epidemiology Criteria (STROBE) [18].

\subsection{Participants}

The initial sample was composed of 53 women, belonging to the Senior Citizens University of the University of Extremadura (Spain). We chose women over 50 years of age, since the highest risk of falls has been demonstrated in older adult women starting from that age $[19,20]$. The inclusion criteria were: not to present a personal history related to vestibular, peripheral or central pathology; not to present cranioencephalic, osteoarticular or muscular traumas that prevented a correct upright stance and/or ambulation; not to be taking medication that affected the posture such as sedatives of the vestibular apparatus, antidepressants or anxiolytics; and not to exhibit dizziness or vertigo at the time of study. As an exclusion criterion, none of the women should present percentage values below normal according to the indicators given by the platform.

Of the total sample, 4 cases were ruled out for exhibiting pathological values in the somatosensory system once the average values of the Dinascan/IBV force platform were identified. Finally, a sample of 49 women, with an average age of $62.84 \pm 7.76$ years (minimum 50, maximum 78), a BMI of $26.08 \pm 3.57$, and with normal balance assessment percentages $(\mathrm{SOM}=97 \%$, VIS $=100 \%$, VES $=100 \%)$, freely agreed to participate in the study.

\subsection{Data Collection Protocol}

Postural stability in an upright stance was quantified by static posturography using the Dinascan/IBV force platform $(600 \times 370 \mathrm{~mm}$ of active area, $100 \mathrm{~mm}$ in height and $25 \mathrm{~kg}$ in weight) using the NedSVE/IBV ${ }^{\circledR}$ system, (Valencia, Spain) (Figure 1).

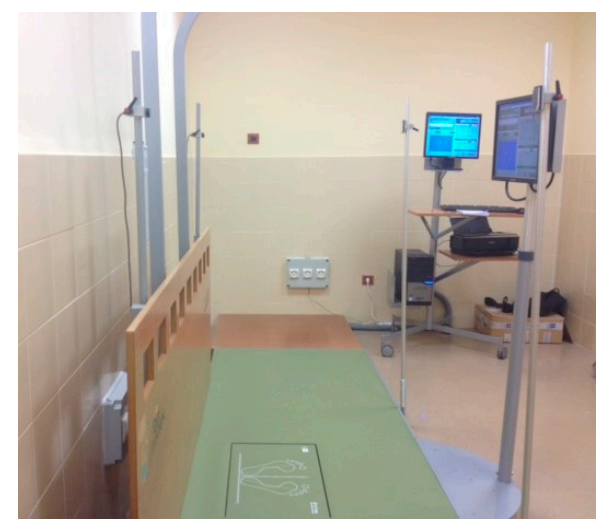

Figure 1. Dinascan/IBV force platform.

Participants were asked to find the most stable position while barefoot with their arms relaxed on either side of the body, with their heels together and toes apart at a $30^{\circ}$ angle. Four static conditions with increasing difficulty were measured, each with a duration of 30 s: Romberg test with eyes open (ROA), Romberg test with eyes closed (ROC), Romberg test with eyes open placing a foam rubber pad under the feet (RGA) and Romberg test with eyes closed and foam rubber pad under the feet (RGC). The foam rubber pad had a thickness of $9 \mathrm{~cm}$ and a density of $56.7 \mathrm{~kg} / \mathrm{m}^{3}$, the penetration resistance was $25 \%(246 \mathrm{~N})$, and the size was the same as that of the platform (Figure 2). 


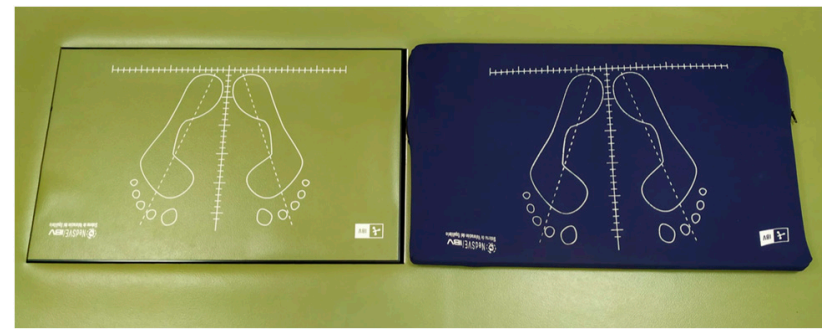

Figure 2. Foam rubber pad used in RGA and RGC.

The balance assessment is based on the comparison of the parameters that best discriminate the pathology of the general population with those obtained from patterns of normality segmented by age (database of the Institute of Biomechanics of Valencia). Ratings are displayed in $\%$ so that results other than $100 \%$ reflect discrepancy with respect to normal values. It is considered pathological when the results are less than $95 \%$, indicating that these subjects are more likely to present an alteration in the studied system.

The variables studied in the tests were:

- Body sway area $\left(\mathrm{mm}^{2}\right)$ : approximate area in which the subject's balance takes place. To obtain this calculation, the software application determines an ellipse that encompasses a group of points that represent the subject's trajectory during the duration of the test.

- Maximum anteroposterior (AP) and mediolateral (ML) displacement (mm): these represent the furthest point reached by the centers of pressure in the anteroposterior and mediolateral axes during the recording time.

\subsection{Statistical Analysis}

The statistical analysis was performed using the SPSS software package version 26.0 (SPSS Inc., Chicago, IL, USA). The normality distribution of the variables was determined with the Shapiro-Wilk test. A univariate analysis of variance (ANOVA) was conducted to assess the changes in the study variables, using the Bonferroni adjustment for post hoc pairwise comparisons.

Paired differences between AP and ML displacement were compared using the Wilcoxon test. To determinate the influence of age on the study measures, a Pearson (r) or Spearman correlation (rho) analysis was performed according to distribution of the variables. The significance level was established as $p<0.05$.

\section{Results}

A total of 59 women with a mean age of $62.84 \pm 7.77$ years in ranges of 50-55 $(n=7)$, 55-60 $(n=8), 60-65(n=13), 65-70(n=12), 70-75(n=4)$ and 75-80 $(n=5)$ were recruited. Anthropometric parameters of women are shown in Table 1.

Table 1. Anthropometric characteristics of participants.

\begin{tabular}{cccc}
\hline & Mean \pm SD & Minimum & Maximum \\
\hline Age & $62.84 \pm 7.77$ & 50 & 78 \\
Weigh & $65.07 \pm 9.05$ & 40.6 & 78.1 \\
Heigh & $157.94 \pm 5.7$ & 143 & 168 \\
IMC & $26.08 \pm 3.57$ & 19.68 & 35.73 \\
\hline
\end{tabular}

In the ANOVA, we detected significant interaction based on the test performed for the three variables analyzed. Table 2 lists its average values. 
Table 2. Changes and levels of significance $(p=0.05)$ in the variables according to the study situation. ROA: Romberg, eyes open; ROC: Romberg, eyes closed; RGA: Romberg, foam, eyes open; RGC: Romberg, foam, eyes closed.

\begin{tabular}{cccccc}
\hline & ROA & ROC & RGA & RGC & $p$ \\
\hline $\begin{array}{c}\text { Body sway area } \\
\left(\mathrm{mm}^{2}\right)\end{array}$ & $29.81 \pm 18.27$ & $43.15 \pm 28.64$ & $48.70 \pm 37.57$ & $143.07 \pm 115.35$ & 0.001 \\
$\begin{array}{c}\text { AP displacement } \\
(\mathrm{mm})\end{array}$ & $18.15 \pm 8.39$ & $23.30 \pm 10.03$ & $22.27 \pm 7.93$ & $38.03 \pm 14.89$ & 0.001 \\
$\begin{array}{c}\text { ML displacement } \\
(\mathrm{mm})\end{array}$ & $10.06 \pm 3.09$ & $13.84 \pm 6.71$ & $15.60 \pm 12.45$ & $24.56 \pm 13.31$ & 0.001 \\
\hline
\end{tabular}

In the pairwise comparison, a statistically significant difference was observed in the Romberg test with closed eyes and foam rubber pad (RGC) between the body sway area $\left(\mathrm{F}=33.21 ; p=0.01 ; \eta^{2}=1\right)$, ML displacement $\left(\mathrm{F}=19.15 ; p=0.01 ; \eta^{2}=1\right)$ and AP displacement $\left(\mathrm{F}=32.44 p=0.01 ; \eta^{2}=1\right)$ variables.

When comparing the average values of the variables AP displacement and ML displacement in each of the four measured situations (ROA, ROC, RGA, RGC), we observed that the change detected is statistically significant $(p<0.001)$.

Table 3 shows the influence of age on each variable. We observe that there is no significant correlation.

Table 3. Correlation between age and variables in each situation. ${ }^{* *}$ Pearson coefficient $(\mathrm{r})$.

\begin{tabular}{cccccccccc}
\hline & \multicolumn{2}{c}{ ROA } & \multicolumn{2}{c}{ ROC } & \multicolumn{2}{c}{ RGA } & \multicolumn{2}{c}{ RGC } \\
\hline & r/rho & $p$ & r/rho & $p$ & rho & $p$ & rho & $p$ \\
\hline Body sway area & -0.009 & 0.95 & 0.09 & 0.54 & 0.23 & 0.88 & 0.16 & 0.26 \\
AP displacement & $-0.09^{* *}$ & 0.54 & $0.27^{* *}$ & 0.85 & -0.001 & 0.99 & 0.15 & 0.30 \\
ML displacement & 0.18 & 0.21 & 0.22 & 0.12 & 0.19 & 0.18 & 0.12 & 0.40 \\
\hline
\end{tabular}

\section{Discussion}

Static posturography helped us detect balance anomalies as the main preventive method against falls.

Of the 53 women studied, only four had alterations in the somatosensory component, who were subsequently eliminated from the study so as not to interfere with the data on the rest of the women. Of the remaining 49 , none presented values below $100 \%$ in the assessment of the visual and vestibular system. However, although the assessment of the somatosensory system was within the range of normality, in 16 women this value ranged between $95-99 \%$. We could therefore deduce that, without exhibiting pathology, the greatest adaptations occur in this system.

According to the results obtained, where the changes in the variables are statistically significant in the RGC $(p=0.001)$, it can be assumed that the greatest preventive intervention of falls in older people should focus precisely on the improvement of somatosensory or proprioceptive perception.

Although the etiology of falls is complex, there are authors who postulate that falls mostly originate from alteration of the proprioceptive system, making it the most important causal factor. The modification of this system through its main elements-the eyes (convergence) and feet (varus/valgus) — seems essential to obtain postural balance [4]. In this sense, proprioceptive training has been shown to induce positive changes in postural balance and stability $[21,22]$.

It is possible that the use of inappropriate footwear is another factor that influences the results, given that it causes a structural change in the foot and, with it, a modification in proprioception during static loading of the foot [23], although we have not studied the type of footwear that the women usually used. 
According to the results obtained, the age in the sample of women studied does not seem to influence the appearance of alterations in balance. This differs from other studies where balance disturbances due to visual, auditory and somatosensory alterations are directly related to age $[6,24,25]$. However, these studies were carried out in women with an average age greater than those in our sample. In contrast, other research determines that age, by itself, is not a factor that affects the alteration in balance, but it is when combined with different factors that appear especially around the age of 65 . Considering that the average age of our sample was established at $62.84 \pm 7.76$ years, it is possible that these factors were not yet present [26].

The increase in oscillations in older people implies greater instability and, consequently, a greater risk of falls [27]. Our results show greater oscillations in the anteroposterior direction $(p<0.001)$, which is consistent with studies also carried out with older women or with elderly people of both sexes. Since the projection of our center of gravity passes in front of the third sacral vertebra, anteroposterior oscillations in search of postural stability are normal in humans [28,29]. The increase in mediolateral oscillations is associated with mild cognitive impairment [30]. Although we did not assess the cognitive state, a priori, our sample of women did not present any deterioration and therefore no significant oscillations were recorded in this front. It is safe to assume that with the changes that come with aging, by increasing the base of support and the angle of ambulation [31], older people could present greater oscillations in the mediolateral direction, which would need to be verified with other studies.

Our results show that there are no significant differences in the posturographic variables studied in situation 1 (ROA), 2 (ROC) and 3 (RGA), but a situation of clear instability in situation 4 (RGC) is marked with an increase in the three variables studied according to other studies carried out [32,33]. In fact, the values between ROC and RGA are very similar. We observed that, when two systems intervene together, balance remains stable with no significant increases in oscillations. Changes in the feet and eyes seem to be the cause of postural imbalances and their corrections are essential to achieve this balance [4]. In fact, the largest deficit found in the elderly who suffer repeated falls has been in the visual field [34], although these data refer to elderly people with a history of falling, unlike our sample studied.

In the RGC situation, only vestibular function is present, given the cancellation of the other two systems, with a progressive deterioration as age advances [35]. In effect, people with Menière's disease are unable to maintain good stability in the RGC situation, but nevertheless they do have good visual or somatosensory information that improves their stability [36]. In the cases where improvement of vestibular or visual function were not possible, balance rehabilitation would be based on proprioceptive training as a preventative measure against falls. However, we must consider all the multiple causes that could interfere with the loss of balance individually, such as parameters related to muscle function (tone, elasticity, EMG activity) [37].

\section{Conclusions}

Both cancellation of visual and somatosensory afferents could facilitate the appearance of falls because this causes a situation of maximum instability, demonstrated by a significant increase in both body sway area and AP and ML displacements, with no correlation to age.

The posturographic platform confirmed that, although within normal parameters, the only percentage variations occurred in the somatosensory system, which could steer balance training towards somatosensory or proprioceptive improvement as a fundamental pillar in the prevention of falls.

The anteroposterior oscillations are greater than the mediolateral ones, which could be because the women in the study are a healthy population without cognitive impairment. It is necessary to identify each situation individually to establish appropriate preventive measures. 
Author Contributions: Conceptualization, A.G.-M. and E.E.-M.; methodology, E.E.-M. and L.M.F.-S.; data curation and formal analysis L.M.F.-S.; writing-original draft preparation, A.G.-M., B.G.-M.; writing-review and editing, A.C.-M. and J.A.D.-M. All authors have read and agreed to the published version of the manuscript.

Funding: This research received no funding.

Institutional Review Board Statement: The study was conducted according to the guidelines of the Declaration of Helsinki and approved by the Ethics Committe of University of Extremadura.

Informed Consent Statement: Informed consent was obtained from all subjects involved in the study.

Data Availability Statement: Not applicable.

Conflicts of Interest: The authors declare no conflict of interest.

\section{References}

1. Ambrose, A.F.; Paul, G.; Hausdorff, J.M. Risk factors for falls among older adults: A review of the literature. Maturitas 2013, 75, 51-61. [CrossRef]

2. Cuevas-Trisan, R. Balance problems and fall risks in the elderly. Phys. Med. Rehabil. Clin. N. Am. 2017, 28, 727-737. [CrossRef]

3. Estrella-Castillo, D.F.; Euán-Paz, A.; Pinto-Loría, M.L.; Sánchez-Escobedo, P.A.; Rubio-Zapata, H.A. Alteraciones del equilibrio como predictoras de caídas en una muestra de adultos mayores de Mérida Yucatán, México. Rehabilitación 2011, 4, 320-326. [CrossRef]

4. Souza, N.S.; Martins, A.C.G.; Machado, D.C.D.; Dias, K.P.; Nader, S.; Bastos, V.H. The influence of vision-foot axis in morphoestatic balance regulation in elderly. Rev. Neurosci. 2012, 20, 320-327.

5. Gama, Z.A.S.; Gómez-Conesa, A. Factores de riesgo de las caídas en ancianos: Revisión sistemática. Rev. Saúde Pública 2008, 42, 946-956. [CrossRef] [PubMed]

6. Sampedro, J.; Meléndez, A.; Ruiz, P. Análisis comparativo de la relación entre el número de caídas anual y baterías de pruebas de equilibrio y agilidad en personas mayores. Retos Nuevas Tend. Educ. Física Deporte Recreación 2010, 17, $115-117$.

7. Era, P.; Sainio, P.; Koskinen, S.; Haavisto, P.; Vaara, M.; Aromaa, A. Postural balance in a random sample of 7979 subjects aged 30 years and over. Gerontology 2006, 52, 204-213. [CrossRef] [PubMed]

8. Piirtola, M.; Era, P. Force platform measurements as predictors of falls among older people: A review. Gerontology 2006, 52, 1-16. [CrossRef]

9. Lázaro-Del Nogal, M. Fall among older persons. Med. Clin. 2009, 133, 147-153.

10. Bear, M.F.; Connors, B.; Paradiso, M. Neuroscience: Exploring the Brain; Lippincott Williams \& Wilkins: Baltimore, MD, USA, 2007.

11. Sanz, E.M.; Guzmán, R.B.; Cerverón, C.C.; Baydal, J.M. Análisis de la interacción visuo-vestibular y la influencia visual en el control postural. Acta Otorrinolaringol. Española 2004, 55, 9-16. [CrossRef]

12. Brachman, A.; Marszałek, W.; Kamieniarz, A.; Michalska, J.; Pawłowski, M.; Akbas, A.; Juras, G. The Effects of Exergaming Training on Balance in Healthy Elderly Women-A Pilot Study. Int. J. Environ. Res. Public Health 2021, 18, 1412. [CrossRef] [PubMed]

13. Low, D.C.; Walsh, G.S.; Arkesteijn, M. Effectiveness of Exercise Interventions to Improve Postural Control in Older Adults: A Systematic Review and Meta-Analyses of Centre of Pressure Measurements. Sports Med. 2017, 47, 101-112. [CrossRef] [PubMed]

14. Chittrakul, J.; Siviroj, P.; Sungkarat, S.; Sapbamrer, R. Multi-System Physical Exercise Intervention for Fall Prevention and Quality of Life in Pre-Frail Older Adults: A Randomized Controlled Trial. Int. J. Environ. Res. Public Health 2020, 17, 3102. [CrossRef] [PubMed]

15. Maki, B.E.; Sibley, K.M.; Jaglal, S.B.; Bayley, M.; Brooks, D.; Fernie, G.R.; Flint, A.J.; Gage, W.; Liu, B.A.; McIlroy, W.E.; et al. Reducing fall risk by improving balance control: Development, evaluation and knowledge-translation of new approaches. J. Saf. Res. 2011, 42, 473-478. [CrossRef]

16. Vega, R.L.; Ruiz, M.C.L. Stabilometry and quality of life in the spinal pain. An analytic transversal study. Fisioterapia 2005, 27, 129-137.

17. Visser, J.E.; Carpenter, M.G.; Van der Kooij, H.; Bloem, B.R. The clinical utility of posturography. Clin. Neurophysiol. 2008, 119, 2424-2436. [CrossRef] [PubMed]

18. Von Elm, E.; Altman, D.G.; Egger, M.; Pocock, S.J.; Gøtzsche, P.C.; Vandenbroucke, J. Strobe: Annals of internal medicine academia and clinic the strengthening the reporting of observational studies in Epidemiology (STROBE) Statement: Guidelines for reporting. Lancet 2007, 370, 1453-1457. [CrossRef]

19. Carrasco, C.; Tomas-Carus, P.; Bravo, J.; Pereira, C.; Mendes, F. Understanding fall risk factors in community-dwelling older adults: A cross-sectional study. Int. J. Older People Nurs. 2020, 15, e12294. [CrossRef]

20. Borah, D.; Wadhwa, S.; Singh, U.; Yadav, S.L.; Bhattacharjee, M.; Sindhu, V. Age related changes in postural stability. Indian J. Phisiol. Pharmacol. 2007, 51, 395-404. 
21. Martínez-Amat, A.; Hita-Contreras, F.; Lomas-Vega, R.; Caballero-Martínez, I.; Alvarez, P.J.; Martínez-López, E. Effects of 12-week proprioception training program on postural stability, gait, and balance in older adults: A controlled clinical trial. J. Strength Cond. Res. 2013, 27, 2180-2188. [CrossRef] [PubMed]

22. Espejo-Antúnez, L.; Pérez-Mármol, J.M.; Cardero-Durán, M.A.; Toledo-Marhuenda, J.V.; Albornoz-Cabello, M. The Effect of Proprioceptive Exercises on Balance and Physical Function in Institutionalized Older Adults: A Randomized Controlled Trial. Arch. Phys. Med. Rehabil. 2020, 101, 1780-1788. [CrossRef]

23. Mourey, F. Los pies y el envejecimiento: Efectos sobre el equilibrio y la deambulación. EMC-Podología 2011, 2, 1-10. [CrossRef]

24. Baydal-Bertomeu, J.M.; Viosca-Herrero, E.; Ortuño-Cortés, M.A.; Quinza-Valero, V.; Garrido-Jaén, D.; Vivas-Broseta, M.J. Estudio de la eficacia y fiabilidad de un sistema de Posturografía en comparación con la escala de Berg. Rehabilitación 2010, 44, 304-310. [CrossRef]

25. Takeshima, N.; Islam, M.M.; Rogers, M.E.; Koizumi, D.; Tomiyama, N.; Narita, M.; Rogers, N.L. Pattern of age-associated de-cline of static and dynamic balance in community-dwelling older women. Geriatr. Gerontol. Int. 2014, 14, 556-560. [CrossRef] [PubMed]

26. Howcroft, J.; Lemaire, E.D.; Kofman, J.; William, E.; McIlroy, W.E. Elderly fall risk prediction using static posturography. PLoS ONE 2017, 12, e0172398. [CrossRef]

27. Merlo, A.; Zemp, D.; Zanda, E.; Rocchi, S.; Meroni, F.; Tettamanti, M.; Recchia, A.; Lucca, U.; Quadri, P. Postural stability and history of falls in cognitively able older adults: The Canton Ticino study. Gait Posture 2012, 36, 662-666. [CrossRef] [PubMed]

28. Olchowik, G.; Czwalik, A.; Kowalczyk, B. The Changes in Postural Stability of Women in Early Old Age. J. Nutr. Health Aging 2020, 24, 739-744. [CrossRef]

29. Oliveira-Borges, A.P.; Oliveira-Carneiro, J.A.; Zaia, J.E.; Oliveira-Carneiro, A.A.; Massaiti-Takayanagui, O. Evaluation of pos-tural balance in mild cognitive impairment through a three-dimensional electromagnetic system. Braz. J. Otorrinolaringol. 2016, 82, 433-441. [CrossRef] [PubMed]

30. Shin, B.M.; Han, S.J.; Jung, J.H.; Kim, J.E.; Fregni, F.J. Effect of mild cognitive impairment on balance. Neurol. Sci. 2011, 305, 121-125. [CrossRef]

31. Cavalheiro, G.; Almeida, M.; Pereira, A.; Andrade, A. Study of age-related changes in postural control during quiet standing through linear discriminant analysis. BioMed. Eng. OnLine 2009, 8, 35. [CrossRef]

32. Ortuño-Cortés, M.A.; Martín-Sanz, E.; Barona-de Guzmán, R. Static posturography versus clinical tests in elderly people with vestibular pathology. Acta Otorrinolaringol. Esp. 2008, 59, 334-340. [CrossRef]

33. Martín-Sanz, E.; Barona De Guzmán, R.; Comeche-Cerverón, R.; Baydal, J.M. Analysis of the interaction between visual and vestibular influence in postural control. Acta Otorrinolaringol. Esp. 2004, 55, 9-16. [CrossRef]

34. González-Ramírez, A.; Lázaro del NogaL, M.; Ribera-Casado, J.M. Valoración de los sistemas de control postural en ancianos con caídas de repetición. Rev. Esp. Geriatr. Gerontol. 2008, 43, 71-75. [CrossRef]

35. Karmali, F.; Bermúdez-Rey, M.C.; Clark, T.K.; Wang, W.; Merfeld, D.M. Multivariate Analyses of Balance Test Performance, Vestibular Thresholds, and Age. Front. Neurol. 2017, 8, 578. [CrossRef]

36. Domènech-Vadillo, E.; Montes-Jovellar, L.; Rey-Martínez, J.; Pérez-Fernández, N. Normal and vestibular patterns in dynamic posturography in patients with Meniere's disease. Acta Otorrinolaringol. Esp. 2010, 61, 34-40. [CrossRef]

37. Ibeneme, S.C.; Exanem, C.; Ezuma, A.; LLoanus, I.N.; Lasebikian, N.; Lasebikian, O.; Oboh, O.C. Walking balance is mediated by muscle strength and bone mineral density in postmenopausal women: An observational study. BMC Musculoskelet. Disord. 2018, 15, 84. [CrossRef] [PubMed] 